\title{
Flux growth of magnetoplumbite-type strontium ferrite single crystals with La-Co co-substitution
}

\author{
A. Shimoda, K. Takao, K. Uji, T. Waki, Y. Tabata, H. Nakamura \\ Department of Materials Science and Engineering, Kyoto University, Kyoto 606-8501, \\ Japan
}

\begin{abstract}
The $\mathrm{Na}_{2} \mathrm{O}$ flux method was successfully applied in the single crystal synthesis of the magnetoplumbite-type strontium ferrite with La-Co co-substitution $\left(\mathrm{Sr}_{1-x} \mathrm{La}_{x} \mathrm{Fe}_{12-y} \mathrm{Co}_{y} \mathrm{O}_{19}\right)$, which is a familiar base material for commercial permanent magnets. The initial amount of $\mathrm{Na}_{2} \mathrm{O}$ flux was fixed in the molar ratio of $\mathrm{Na} /(\mathrm{Sr}+\mathrm{La})=5.17$. Composition analysis revealed discordance between La and Co concentrations $(x>y)$ in the obtained crystals, indicating that the extra charge introduced by the $\mathrm{Co}^{2+}$ substitution for $\mathrm{Fe}^{3+}$ is not compensated by $\mathrm{La}^{3+}$ for $\mathrm{Sr}^{2+}$. In the present growth condition, the necessary amount of La is nearly twice that of $\mathrm{Co}(y / x \simeq 0.55)$, suggesting valence instability of an appreciable amount of $\mathrm{Fe}^{3+}$ to $\mathrm{Fe}^{2+}$. Single crystalline magnetization measurements showed that the substitution markedly enhances the magnetic anisotropy and slightly raises the saturation magnetization. Remaining problems, which should be resolved before the experimental determination of the Co site occupation, are also discussed.
\end{abstract}

Keywords: magnetoplumbite-type strontium ferrite, single crystal, magnetic anisotropy, La-Co co-substitution

\section{Introduction}

Magnetoplumbite-type (M-type) strontium ferrite, $\mathrm{SrFe}_{12} \mathrm{O}_{19}$ (will be called $\mathrm{SrM}$ ), has been one of important base materials for the permanent magnet because of its high cost performance and chemical stability in spite of much smaller 5 producible magnetic flux than rare-earth based permanent magnets. The Mtype crystal structure has hexagonal symmetry with space group $P 6_{3} / m m c$, in which there are five crystallographically inequivalent Fe sites; $2 a, 2 b, 4 f_{1}$, $4 f_{2}$, and $12 k$ with different oxygen coordinations (see Table $\mathbb{U}$ ). All Fe ions are trivalent with the $S=5 / 2$ spin quantum number corresponding to the spin 10 moment of $5 \mu_{\mathrm{B}}$. The magnetic moments direct uniaxially along $c$ axis, with majority spin at $2 a, 2 b$, and $12 k$ and minority spin at $4 f_{1}$ and $4 f_{2}$, resulting in

Email address: nakamura.hiroyuki.2w@kyoto-u.ac.jp (H. Nakamura)

Preprint submitted to Journal of Solid State Chemistry

April 19, 2016

(C) 2016. This manuscript version is made available under the Elsevier user license

http://www.elsevier.com/open-access/userlicense/1.0/ 
a ferrimagnetic spin structure with $20 \mu_{\mathrm{B}}$ per formula unit (f.u.) at the ground state.

The simultaneous substitution of La and Co in SrM (will be denoted by La-Co SrM) resulted in marked improvement in the magnetic performance [I]] The improved performance has been discussed along with enhancement in the magnetocrystalline anisotropy expected from the single ion anisotropy of $\mathrm{Co}^{2+}$ $\left(3 d^{6}\right)$ with residual angular momentum [2]. Since crystal field splitting of $3 d$ orbitals in oxides is dominated by oxygen coordination, it is essential to deter20 mine experimentally Co site occupation to reveal the origin of the anisotropy. Although a number of works have already been done, a consensus on the Co site occupation has not been achieved; for example, $2 a$ and $4 f_{2}$ by conventional methods including Mössbauer spectroscopy [3, 4, 5], $4 f_{1}$ and $4 f_{2}$ by nuclear magnetic resonance (NMR) [6], $2 a, 4 f_{1}$, and $12 k$ by a combined study of ex25 tended X-ray absorption fine structure (EXAFS), neutron diffraction, and X-ray magnetic circular dichroism (XMCD) [7]].

The disagreement is primarily ascribed to the presence of a huge number of unknown parameters which should be determined in the experimental analyses, in addition to unsubstantiated assumptions. For example, the extra charge re30 sulted from the $\mathrm{La}^{3+}$ substitution has often been assumed to be compensated entirely by $\mathrm{Co}^{2+}$. However, this assumption disagrees with a resent phase diagram study $[\mathbf{8}]$, which indicates that $\mathrm{Fe}_{2} \mathrm{O}_{3}$ and $\mathrm{LaFeO}_{3}$ are included as second phases even when the preparation is started from the equal amounts of La and Co raw materials [9]. Generally, second phases are poorly crystallized and the 35 amount is often too poor to be detected by X-ray diffraction (XRD). The real chemical formula of La-Co SrM should be $\mathrm{Sr}_{1-x} \mathrm{La}_{x} \mathrm{Fe}_{12-y} \mathrm{Co}_{y} \mathrm{O}_{19}$ with $x>y$. In this case, the charge variation associated with the $\mathrm{La}^{3+}$ substitution is likely to be compensated by not only the $\mathrm{Co}^{2+}$ substitution but also the reduction of $\mathrm{Fe}^{3+}$ to $\mathrm{Fe}^{2+}$. Thus, the as-mixed nominal values are inappropriate as the actual compositions.

Single crystals, free from second phases, are more appropriate for reducing unknown parameters in experimental analyses. Single crystals of $\mathrm{SrFe}_{12} \mathrm{O}_{19}$ and its related materials have been synthesized by various methods such as a floating zone method under high oxygen pressure [III], a traveling solvent floating zone 45 method [1]], and flux methods with various flux [12, [13, 144, [15]. Since $\mathrm{SrFe}_{12} \mathrm{O}_{19}$ melts incongruently in ambient atmosphere [16]], the flux method is suitable to obtain single crystals in ambient conditions. Although single crystals in which either the $\mathrm{Sr}$ or Fe site is replaced by another element have been synthesized [177, [18], to the best our knowledge, doubly substituted single crystals have not been reported so far.

In this article, we report single crystal growth of La-substituted SrM (will be abbreviated as La $\mathrm{SrM}$ ) and La-Co SrM using the $\mathrm{Na}_{2} \mathrm{O}$ flux method and magnetic properties of the obtained crystals. 
Table 1: Crystallographic Fe sites in $\mathrm{SrFe}_{12} \mathrm{O}_{19}$ with space group $P 6_{3} / m m c$ and magnetic moment directions at the sites.

\begin{tabular}{ccc}
\hline \hline $\begin{array}{c}\text { Wyckoff } \\
\text { notation }\end{array}$ & $\begin{array}{c}\text { oxygen } \\
\text { coordination }\end{array}$ & $\begin{array}{c}\text { moment } \\
\text { direction }\end{array}$ \\
\hline $2 a$ & octahedral & $\uparrow$ \\
$2 b$ & bipyramidal & $\uparrow$ \\
$4 f_{1}$ & tetrahedral & $\downarrow$ \\
$4 f_{2}$ & octahedral & $\downarrow$ \\
$12 k$ & octahedral & $\uparrow$ \\
\hline \hline
\end{tabular}

\section{Experiments}

55 (La-Co SrM) by the $\mathrm{Na}_{2} \mathrm{O}$ flux method in a platinum crucible [18]. $\mathrm{Na}_{2} \mathrm{CO}_{3}$ (purity $99.99 \%), \mathrm{SrCO}_{3}(99.9 \%), \mathrm{La}_{2} \mathrm{O}_{3}(99.9 \%), \mathrm{Fe}_{2} \mathrm{O}_{3}(99.99 \%)$, and $\mathrm{Co}_{3} \mathrm{O}_{4}(99.9 \%)$ were weighted and mixed well in an agate mortar for several hours. In the present synthesis condition, the initial amount of the $\mathrm{Na}_{2} \mathrm{O}$ flux was fixed in a amounts of $\mathrm{La}$ and $\mathrm{Co}$ in atomic percent. The mixture, set in a Pt crucible, was heated in a furnace with a molybdenum disilcide heater under ambient atmosphere. The mixture was kept at $1450^{\circ} \mathrm{C}$ for $12 \mathrm{~h}$, cooled down to $1000^{\circ} \mathrm{C}$ in the rate of $2.5^{\circ} \mathrm{C} / \mathrm{h}$, and followed by furnace-cooling below $1000^{\circ} \mathrm{C}$ to room temper-

65 ature. Obtained single crystals were typically in the dimension of $5 \times 5 \times 0.1$ $\mathrm{mm}^{3}$, in which hexagonal shapes were seen on the surface. The crystals were separated by dissolving residual in diluted hydrochloric acid, and followed by annealing in air at $1200^{\circ} \mathrm{C}$ for 6 days.

A part of obtained crystals were crushed into powder to measure XRD ferrite and to estimate lattice constants. As an example, the XRD pattern of a powdered sample $\left(\mathrm{Sr}_{1-x} \mathrm{La}_{x} \mathrm{Fe}_{12-y} \mathrm{Co}_{y} \mathrm{O}_{19}\right.$ with $x=0.378$ and $\left.y=0.212\right)$ is shown in Fig. . Compositions of metallic elements, $x$ and $y$, were analyzed using wavelength-dispersive X-ray (WDX) spectrometer (INCA Wave 500, Oxford

75 Instruments) attached to a scanning electron microscope (S-3500H, Hitachi), which can separate thoroughly Co and Fe spectra. Characteristic X-rays, Sr$L \alpha, \mathrm{La}-L \alpha, \mathrm{Fe}-K \alpha$, and $\mathrm{Co} K \alpha$, were examined at an acceleration voltage of 25 $\mathrm{kV}$. The X-ray intensities were calibrated by using single crystals of $\mathrm{SrFe}_{12} \mathrm{O}_{19}$, $\mathrm{LaAlO}_{3}$, and metallic Co as reference materials. Intensities measured at at least

80 three points in each sample were averaged to determine the compositions. The ratio of $(\mathrm{Fe}+\mathrm{Co}) /(\mathrm{Sr}+\mathrm{La})$ always exceeds 12 because temperature fluctuation of the pentaerythritol (PET) analyzing crystal leads to unavoidable peak drift of the $\operatorname{Sr}-L \alpha$ line with a relatively long wavelength $(=6.86 \AA)$, resulting in underestimation $(2-3 \%)$ of the $\mathrm{Sr}$ intensity. Here we show the concentration in 
applied WDX to check the possible inclusion of $\mathrm{Na}$ in the crystals. A trace of $\mathrm{Na}$ signal was occasionally detected, but did not indicate convincingly appreciable inclusion of $\mathrm{Na}$ in the crystals.

Magnetization $(M)$ was measured at $5 \mathrm{~K}$ in fields $(H)$ up to $70 \mathrm{kOe}$ using a SQUID magnetometer (MPMS, Quantum Design) installed in the LTM center of Kyoto University. Magnetization for the easy axis $(H \perp c)$ and the hard axis $(H \| c)$ was independently measured for the identical crystal. The demagnetization correction was done by taking into account the sample shape. The anisotropy constant, $K_{1}$, in the dimension of energy was estimated by inte-

95 grating the area surrounded by the easy- and hard-axis $M-H$ curves. Here, we discuss the anisotropy in the form of the anisotropy field, $H_{\mathrm{A}}=2 K_{1} / M_{\mathrm{s}}$ where $M_{\mathrm{s}}$ is the saturation magnetization, which is compared with literature data estimated by the singular point detection (SPD) method for polycrystalline samples [I.9]. The Curie temperature, $T_{\mathrm{C}}$, was determined from the magnetization measured by a vibrating sample magnetometer (VSM-5, Toei Industry).

\section{Results}

\section{1. $\mathrm{Sr}_{1-x} \mathrm{La}_{x} \mathrm{Fe}_{12} \mathrm{O}_{19}$ ( $\left.\mathrm{La} \mathrm{SrM}\right)$}

WDX analysis manifested that La was successfully doped in single crystalline La SrM. In the present work, the upper limit of the La concentration, $x$, is $\sim 0.4$. This is roughly consistent with $x<0.5$ at $1300^{\circ} \mathrm{C}$ in a literature [20]. Although $\mathrm{La} \mathrm{SrM}$ has been synthesized in the range of $0 \leq x \leq 1$, rapid cooling is necessary for higher La concentrations.

Figure 『 shows typical easy- and hard-axis magnetization curves measured at $5 \mathrm{~K}$ for selected samples $(x=0$ and 0.395$)$. The easy-axis magnetization is insensitive to the substitution, whereas the hard-axis component saturates at a lower field for $x=0.395$, indicating reduced anisotropy in La SrM. The hardaxis magnetization bends slightly on approaching the saturation, which can be interpreted phenomenologically as the appearance of higher order terms in the anisotropy energy.

${ }_{115}$ As seen in Fig. 3 (a), the lattice constant, $a$, increases slightly with $x$, whereas $c$ markedly decreases, which is ascribed to the smaller ionic volume of $\mathrm{La}^{3+}$ than $\mathrm{Sr}^{2+}$. Figure 3 (b) shows the saturation magnetization, $M_{\mathrm{s}}$, at $5 \mathrm{~K}$. The dashed line represents the calculated magnetization for La SrM based on the GGA $+U$ method [2I]. In a literature [ 22$], M_{\mathrm{S}}$ decreases monotonically with $x$. In our case, such a tendency is not convincing because of the limited number of data. In contrast to $M_{\mathrm{s}}$, the anisotropy field, $H_{\mathrm{A}}$, drastically decreases with $x$ as seen in Fig. 3 (c). On the other hand, it should be noted that $H_{\mathrm{A}}$ for the other end compound, $\mathrm{LaFe}_{12} \mathrm{O}_{19}$, is enhanced up to $40 \mathrm{kOe}$ (at the lowest temperature) [23]. This means that $H_{\mathrm{A}}$ takes a minimum at a certain $x$, as actually observed 125 at $x \sim 0.5$ [24]. Although the origin of this characteristic variation has not been elucidated, it may be related to the appearance of $\mathrm{Fe}^{2+}$ with unquenched orbital momentum and occupation sites of $\mathrm{Fe}^{2+}$ : The enhancement in $\mathrm{LaFe}_{12} \mathrm{O}_{19}$ was attributed to $\mathrm{Fe}^{2+}$ appeared at $2 a[2.3,[25]$. On the other hand, at small $x$, it 


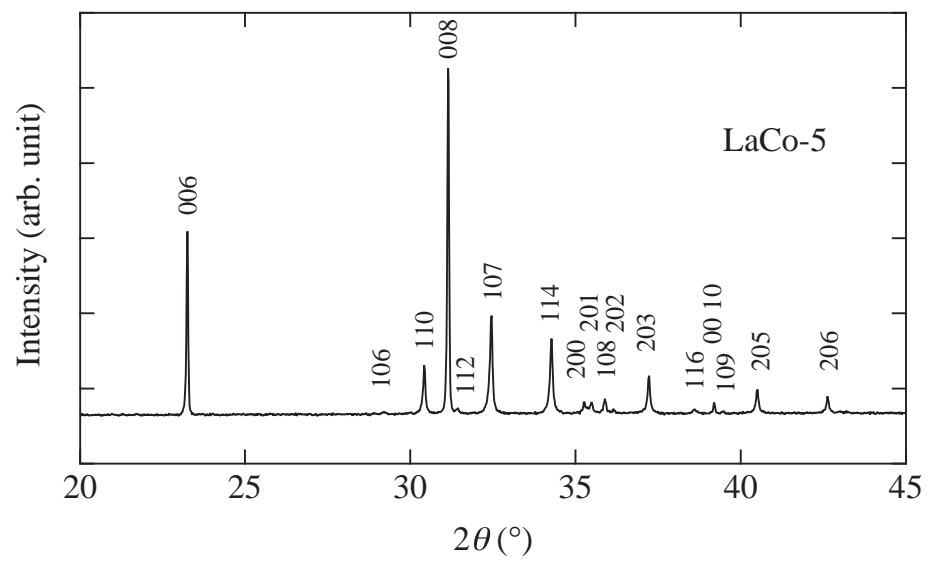

Figure 1: (Color online) X-ray diffraction pattern for powdered single crystals of $\mathrm{Sr}_{1-x} \mathrm{La}_{x} \mathrm{Fe}_{12-y} \mathrm{Co}_{y} \mathrm{O}_{19}$ with $x=0.378$ and $y=0.212$. The basel plane of the powder are preferentially oriented.

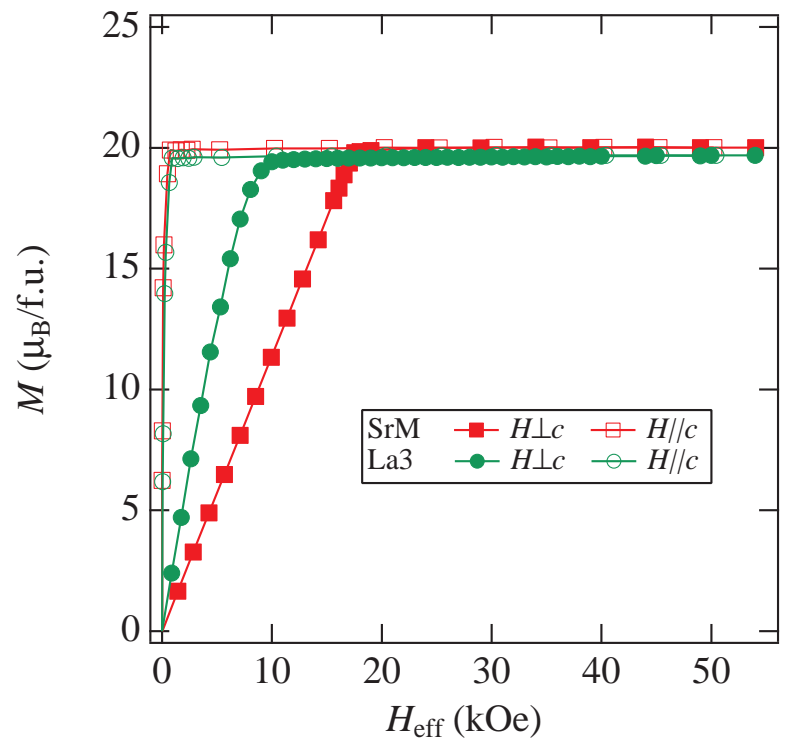

Figure 2: (Color online) Typical magnetization curves for easy- (red) and hard-axes (blue) at $5 \mathrm{~K}$ for $\mathrm{Sr}_{1-x} \mathrm{La}_{x} \mathrm{Fe}_{12} \mathrm{O}_{19}$ with $x=0$ and 0.395 . 
Table 2: Parameters obtained for single crystalline $\mathrm{Sr}_{1-x} \mathrm{La}_{x} \mathrm{Fe}_{12} \mathrm{O}_{19}$. Values in [ ] indicate nominal La compositions before the heat treatment.

\begin{tabular}{ccccccc}
\hline \hline Sample & $x$ & $\begin{array}{c}a \\
(\AA)\end{array}$ & $\begin{array}{c}c \\
(\AA)\end{array}$ & $\begin{array}{c}M_{\mathrm{s}} \\
\left(\mu_{\mathrm{B}} / \mathrm{f} . \mathrm{u} .\right)\end{array}$ & $\begin{array}{c}H_{\mathrm{A}} \\
(\mathrm{kOe})\end{array}$ & $\begin{array}{c}T_{\mathrm{C}} \\
(\mathrm{K})\end{array}$ \\
\hline SrM & $0[0]$ & $5.8818(5)$ & $23.0332(7)$ & $20.05(12)$ & 17.50 & 738 \\
La1 & $0.192(1)[0.15]$ & $5.8823(5)$ & $23.0222(1)$ & $20.02(6)$ & 11.27 & 730 \\
La2 & $0.261(3)[0.20]$ & $5.8824(3)$ & $23.0206(4)$ & $20.17(5)$ & 10.28 & 724 \\
La3 & $0.395(1)[0.46]$ & $5.8830(4)$ & $23.0151(2)$ & $19.69(7)$ & 7.77 & 720 \\
\hline \hline
\end{tabular}

was claimed that $\mathrm{Fe}^{2+}$ occupy the sites other than $2 a$ and negatively contribute to the anisotropy [24]. ${ }^{57} \mathrm{Fe}$ Mössbauer study on La SrM, however, suggests $\mathrm{Fe}^{2+}$ ions present only at $2 a[22]$. (Recent NMR study supports this [26].) A single crystalline Mössbauer study would give a hint to this issue. The Curie temperature, $T_{\mathrm{C}}$, decreases with $x$ (Fig. B (d)), similarly to other substituted systems. For La SrM, $T_{\mathrm{C}}$ varies linearly between $740 \mathrm{~K}$ for $\mathrm{SrFe}_{12} \mathrm{O}_{19}$ and 695 ${ }_{135} \mathrm{~K}$ for $\mathrm{LaFe}_{12} \mathrm{O}_{19}[27]$.

\section{2. $\mathrm{Sr}_{1-x} \mathrm{La}_{x} \mathrm{Fe}_{12-y} \mathrm{Co}_{y} \mathrm{O}_{19}$ ( $\mathrm{La}-\mathrm{Co} \mathrm{SrM}$ )}

In WDX analysis of the identical La-Co SrM sample, we observed both La and Co signals, indicating successful La-Co co-substitution in SrM. The WDXdetermined La concentration, $x$, is plotted against the Co concentration, $y$, in 140 Fig. $\mathbb{\theta}$, where always $x>y$. The upper limits were $x \simeq 0.5$ and $y \simeq 0.3$. It is likely that rapid cooling is necessary to obtain samples with large $x$ and $y$ [8] similarly to La SrM. The present WDX analysis confirmed that the charge compensation between $\mathrm{La}^{3+}$ and $\mathrm{Co}^{2+}$ is not fulfilled. Tenaud et al. [9] reported a ratio of $y / x=0.75$ as the upper limit for powder samples. Our $y / x$ values are 145 rather close to 0.55 (except LaCo6 marked with an asterisk). These different values may be ascribed to different sample preparation conditions; the surface area exposed to air is limited in the flux method. These results strongly suggest that $\mathrm{Fe}^{3+}$ is partly reduced to $\mathrm{Fe}^{2+}$ in La-Co SrM. In LaCo6, $y$ is accidentally small. The presence of the La SrM series implies that $y$ can vary without 150 changing $x$. In other words, $y / x=0.55$ is the upper limit in the present sample preparation condition. In a preliminary experiment, we have confirmed that the value of $y / x$ increases with increasing oxygen partial pressure.

Figure 5 shows easy- and hard-axis magnetization curves for La-Co SrM. The easy-axis magnetization is insensitive to the substitution, whereas the hard-axis 155 component for the substituted sample bends at higher fields and saturates at a higher field than that of the non-doped case, demonstrating directly that the anisotropy is enhanced associated with the La-Co substitution. The present result, together with the data for La SrM, indicates that the anisotropy is enhanced as a result of the Co substitution not by the appearance of $\mathrm{Fe}^{2+}$. The 
Table 3: Parameters obtained for single crystalline $\mathrm{Sr}_{1-x} \mathrm{La}_{x} \mathrm{Fe}_{12-y} \mathrm{Co}_{y} \mathrm{O}_{19}$. Values in [ ] indicate nominal compositions before the heat treatment.

\begin{tabular}{cccccccc}
\hline \hline sample & $x$ & $y$ & $\begin{array}{c}a \\
(\AA)\end{array}$ & $\begin{array}{c}c \\
(\AA)\end{array}$ & $\begin{array}{c}M_{\mathrm{s}} \\
\left(\mu_{\mathrm{B}} / \text { f.u. }\right)\end{array}$ & $\begin{array}{c}H_{\mathrm{A}} \\
(\mathrm{kOe})\end{array}$ & $\begin{array}{c}T_{\mathrm{C}} \\
(\mathrm{K})\end{array}$ \\
\hline SrM & $0[0]$ & $0[0]$ & $5.8818(5)$ & $23.0332(7)$ & $20.05(12)$ & 17.50 & 738 \\
LaCo1 & $0.055(2)[0.04]$ & $0.032(1)[0.04]$ & $5.8819(2)$ & $23.0261(4)$ & $19.83(9)$ & 17.22 & 726 \\
LaCo2 & $0.139(1)[0.10]$ & $0.077(3)[0.10]$ & $5.8821(3)$ & $23.0239(3)$ & $20.07(5)$ & 19.46 & 715 \\
LaCo3 & $0.242(2)[0.15]$ & $0.108(7)[0.15]$ & $5.8824(4)$ & $23.0211(1)$ & $20.33(8)$ & 18.62 & 711 \\
LaCo4 & $0.289(4)[0.20]$ & $0.152(2)[0.20]$ & $5.8829(2)$ & $23.0148(2)$ & $20.19(16)$ & 21.57 & 724 \\
LaCo5 & $0.367(4)[0.35]$ & $0.212(6)[0.35]$ & $5.8837(1)$ & $23.0089(1)$ & $20.22(10)$ & 24.36 & 717 \\
LaCo6 & $0.511(5)[0.50]$ & $0.161(2)[0.50]$ & $5.8837(1)$ & $22.9997(3)$ & $19.38(20)$ & 22.17 & 712 \\
LaCo7 & $0.472(3)[0.80]$ & $0.266(4)[0.80]$ & $5.8840(1)$ & $23.0002(1)$ & $20.39(10)$ & 25.57 & 700 \\
\hline \hline
\end{tabular}

origin of the curved magnetization is of interest and would be essential to explain the anisotropy enhancement. It is highly probable that the this observation is related to a Co-doping induced magnetic structural change, for example, the appearance of non-collinear components, which should be revealed experimentally.

Crystal and magnetic parameters obtained for La-Co SrM are summarized in Table 3 and Fig. [6. The data in Fig. [6 are plotted against the La concentration, $x$, which satisfies $y / x=0.55$ in most cases; the data of LaCo6 will be omitted when referring to $x$ dependence. The lattice parameter, $a$, depends slightly on $x$, whereas $c$ decreases with $x$ (Fig. (a) (a). The volume shrinkage is ascribed to the La substitution. Naively, the increase in $M_{\mathrm{s}}$ with $x$ (Fig. [ (b)) suggests that the moment at the minority spin sites is reduced by the substitution. The marked reduction of $M_{\mathrm{s}}$ for LaCo6 may be due to the appearance of a larger amount of $\mathrm{Fe}^{2+}$, which contributes negatively to $M_{\mathrm{s}}$ similarly to La SrM. In contrast to the La SrM case, $H_{\mathrm{A}}$ increases monotonically with increasing $x$ (Fig. [ (c)) as

175 was reported in literatures [28, 229, 30] . Thus, the Co substitution cancels the negative contribution of $\mathrm{Fe}^{2+}$ to enhance the anisotropy.

\section{Discussion}

The original motivation of the single crystal preparation is to resolve the controvertial situation and determine unambiguously the the Co site occupation in La-Co SrM with the use of well-characterized crystals. However, during the course of the present study, we noticed that the following issues should be resolved before proceeding to the problem of the Co site occupation.

(i) $\mathrm{Fe}^{2+}$ site occupation: If the presence of $\mathrm{Fe}^{2+}$ were undoubtable, the site occupation of $\mathrm{Fe}^{2+}$ should be determined. The possible single ion anisotropy of $\mathrm{Fe}^{2+}$, which depends on local symmetry, would be important similarly 
to that of $\mathrm{Co}^{2+}$. Some ${ }^{57} \mathrm{Fe}$ Mössbauer studies such as Ref. [4] claimed that $\mathrm{Fe}^{2+}$ occupy $2 a$ in La-Co SrM. However, in ${ }^{57} \mathrm{Fe}$ Mössbauer measurements performed for our single crystalline La-Co SrM, we have not obtained convincing evidence on the presence of $\mathrm{Fe}^{2+}[3 \mathrm{3I}]$. Needless to say, the amount and site occupation of $\mathrm{Fe}^{2+}$ correlate significantly with the total magnetization.

(ii) Valence and spin state of Co: Generally it is assumed that the doped $\mathrm{Co}$ is in the divalent high-spin state $\left(S=3 / 2 ; 3 \mu_{\mathrm{B}}\right)$. If the Fe valence were unstable as mentioned above, why not for Co? It is probable that the co valence depends on the occupation site. In addition, symmetry and magnitude of the crystal field, which determines orbital splitting and the spin state, should depend on the site too. Indeed, ${ }^{59} \mathrm{Co}-\mathrm{NMR}$ study has revealed the presence of an anomalously low-frequency signal [6], suggesting small or no moment at the Co site, in addition to high frequency signals coming from high-spin $\mathrm{Co}^{2+}[26]$. Particularly, the origin of the low-frequency ${ }^{59} \mathrm{Co}$ signal should be elucidated at the beginning. Needless to say, if Co were in the trivalent state, the story on the appearance of $\mathrm{Fe}^{2+}$ should severely be modified.

(iii) Magnetic structure: One of reasonable interpretations of the bended magnetization curve observed for not only La-Co SrM but also La SrM is the appearance of non-collinear components in the magnetic structure. So far, most experimental analyses aiming to determine the Co site occupation such as Rietveld refinement of neutron diffraction and XMCD profiles relies on the collinear ferrimagnetic structure in La-Co SrM. If not, the conclusions derived from such experimental analyses would be affected seriously. Neutron diffraction experiments with the use of single crystals would be helpful to solve this problem.

(iv) Co moment direction with respect to host Fe moment: In most experimental analysis, the magnetic moment of doped Co was assumed to be parallel to the host $\mathrm{Fe}^{3+}$ moment. Williams et al. [32], however, pointed out the possibility that Co moments occupied at $4 f_{2}$ and $2 b$ are antiparallel to host $\mathrm{Fe}^{3+}$ moments in $\mathrm{BaFe}_{12-2 x}(\mathrm{CoTi})_{x} \mathrm{O}_{19}$. Such a possibility cannot be neglected in La-Co SrM. Experimentally, it is quite tough to determine these relative directions without the knowledge of the Co site occupation. First-principle calculations may give a hint on this topic.

These factors correlate significantly with each other, implying that all of them should be examined simultaneously to identify the Co site occupation. Although we have not pointed out above, possible deficiency of $\mathrm{Fe}$ and $\mathrm{O}$ atoms may make the problem further complicated.

\section{Summary}

We successfully synthesized single crystals of La and La-Co substituted Mtype strontium ferrite by the $\mathrm{Na}_{2} \mathrm{O}$ flux method. For $\mathrm{Sr}_{1-x} \mathrm{La}_{x} \mathrm{Fe}_{12} \mathrm{O}_{19}$, crystals 
were obtained up to $x \simeq 0.50$. The magnetic anisotropy is reduced with increasing $x$ in the small $x$ region. The origin of this behavior remains to be explained.

230 For $\mathrm{Sr}_{1-x} \mathrm{La}_{x} \mathrm{Fe}_{12-y} \mathrm{Co}_{y} \mathrm{O}_{19}$, the co-substitution does not necessarily mean the equal amounts of La and Co, implying appreciable instability of the 3d-metal valence. The upper limit of the La concentration and the $\mathrm{Co} / \mathrm{La}$ ratio in the present growth condition are $x \simeq 0.50$ and $y / x \simeq 0.55$, respectively. The $y / x$ ratio is likely to depend on the sample preparation condition. The hard-axis

235 magnetization of the La-Co substituted crystals increases non-linearly. The anisotropy is enhanced and the saturation magnetization, $M_{\mathrm{s}}$, increases slightly with the La-Co substitution. To optimize magnetic properties, precise $x$ and $y$ dependencies should be explored. Efforts to identify the Co site occupation are now under way using single crystals.

\section{Acknowledgements}

We thank Y. Takahashi, K. Yoshimura, H. Kobayashi, C. Michioka, H. Sakai, H. Ueda, S. Ikeda, and H. Ikeno for helpful discussion, and K. Kazumi and N. Sasaki for WDX analysis. This study was supported by Japan Science and Technology Agency (JST) under Collaborative Research Based on Industrial Demand "High Performance Magnets: Towards Innovative Development of Next Generation Magnets".

\section{References}

[1] K. Iida, Y. Minachi, K. Masuzawa, M. Kawakami, H. Nishio, H. Taguchi, J. Magn. Soc. Jpn. 23 (1999) 1093-1096. doi:10.3379/jms jmag.23.1093.

[2] Y. Ogata, Y. Kubota, T. Takami, M. Tokunaga, T. Shinokara, IEEE Trans. Magn. 35 (1999) 3334-3336. doi:10.1109/20.800516.

[3] A. Morel, J.-M. Le Breton, J. Kreisel, G. Wiesinger, F. Kools, P. Tenaud, J. Magn. Magn. Mater. 242 (2002) 1405-1407. doi:10.1016/S0304-8853(01) 00962-3.

[4] G. Wiesinger, M. Müller, R. Grössinger, M. Pieper, A. Morel, F. Kools, P. Tenaud, J.-M. Le Breton, J. Kreisel, Phys. Stat. Sol. a 189 (2002) 499508. doi:10.1002/1521-396X (200202)189:2.

[5] L. Lechevallier, J. M. Le Breton, J. Teillet, A. Morel, F. Kools, P. Tenaud, Physica B 327 (2003) 135-139.

[6] M. W. Pieper, F. Kools, A. Morel, Phys. Rev. B 65 (2002) 184402. doi:http://dx.doi.org/10.1103/PhysRevB.65.184402.

[7] Y. Kobayashi, E. Oda, T. Nishiuchi, T. Nakagawa, J. Ceram. Soc. Jpn. 119 (2011) 285-290. doi:10.2109/jcersj2.119.285. 
[21] M. Küpferling, P. Novák, K. Knížek, M. Pieper, R. Grössinger, G. Wiesinger, M. Reissner, J. Appl. Phys. 97 (2005) 10F309. doi:10.1063/ 1.1855710 .

[22] D. Seifert, J. Töpfer, F. Langenhorst, J.-M. Le Breton, H. Chiron, L. Lechevallier, J. Magn. Magn. Mater. 321 (2009) 4045-4051. doi:10.1016/ j.jmmm.2009.07.088.

[23] F. Lotgering, J. Phys. Chem. Solids 35 (1974) 1633-1639. doi:10.1016/ S0022-3697(74)80176-9. 
[24] M. Küpferling, R. Grössinger, M. W. Pieper, G. Wiesinger, H. Michor, C. Ritter, F. Kubel, Phys. Rev. B 73 (2006) 144408. doi:10.1103/ PhysRevB.13.144408.

[25] C. Sauer, U. Köbler, W. Zinn, H. Stäblein, J. Phys. Chem. Solids 39 (1978) 1197-1201. doi:10.1016/0022-3697(78)90096-3.

[26] K. Kouřil, Local structure of hexagonal ferrites studied by NMR, Ph.D. thesis, Prague, 2013.

[27] A. Aharoni, M. Schieber, Phys. Rev. 123 (1961) 807. doi:10.1103/ PhysRev.123.807.

[28] R. Grössinger, J. C. T. Blanco, F. Kools, A. Morel, M. Rossignol, P. Tenaud, in: Proc. 8th Int. Conf. Ferrites, pp. 428-430.

[29] A. Morel, F. Kools, P. Tenaud, R. Grössinger, M. Rossignol, in: Proc. 8th Int. Conf. Ferrites, pp. 434-436.

[30] F. Kools, A. Morel, P. Tenaud, M. Rossignol, O. Isnard, R. Grössinger, J.-M. Le Breton, J. Teillet, in: Proc. 8th Int. Conf. Ferrites, pp. 437-439.

[31] N. Nagasawa, S. Ikeda, A. Shimoda, T. Waki, Y. Tabata, H. Nakamura, H. Kobayashi, Hyperfine Interact. 273 (2016) 39. doi:10.1007/ s10/b1-016-12/2-y.

[32] J. Williams, J. Adetunji, M. Gregori, J. Magn. Magn. Mater. 220 (2000) 124-128. doi:10.1016/S0304-8853(00)00458-3. 


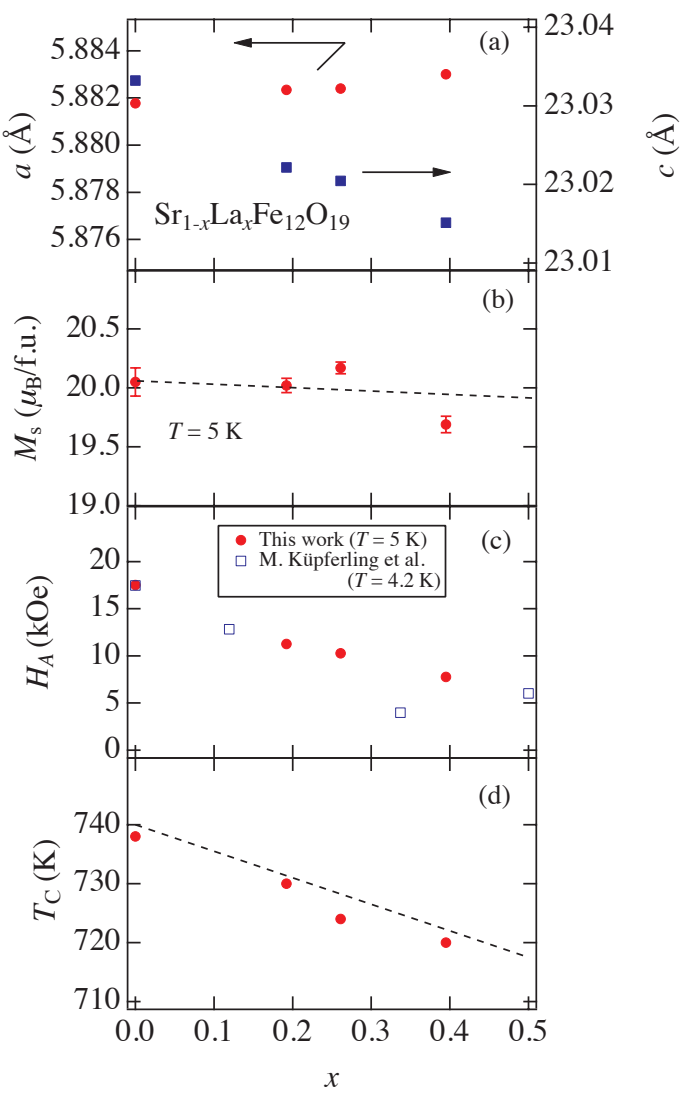

Figure 3: (Color online) (a) La concentration $(x)$ dependencies of lattice constants, $a$ and $c$, (b) saturation magnetization, $M_{\mathrm{s}}$, (c) the anisotropy field, $H_{\mathrm{A}}$, and (d) Curie temperature, $T_{\mathrm{C}}$. The dashed line in (b) represents the calculated magnetization [2]]. In (c), literature data [24] are also included (open squares). The dashed line in (d) represents the interpolation between $T_{\mathrm{C}}$ for $\mathrm{SrFe}_{12} \mathrm{O}_{19}$ and that for $\mathrm{LaFe}_{12} \mathrm{O}_{19}$. 


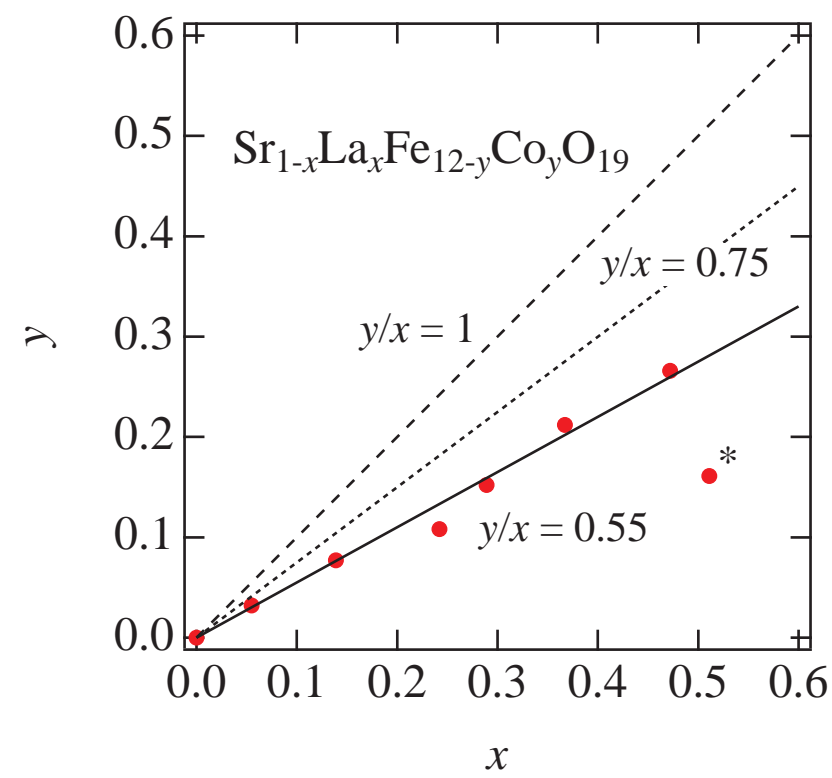

Figure 4: (Color online) WDX-determined Co concentration, $y$, plotted against La concentration, $x$, for $\mathrm{Sr}_{1-x} \mathrm{La}_{x} \mathrm{Fe}_{12-y} \mathrm{Co}_{y} \mathrm{O}_{19}$.

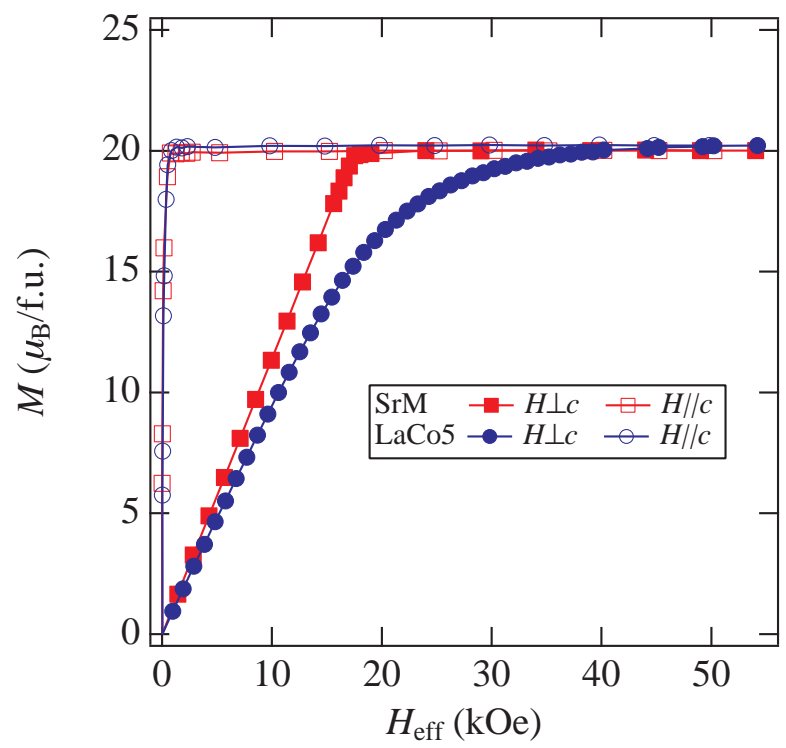

Figure 5: (Color online) Easy- and hard-axis magnetization curves for $\mathrm{Sr}_{1-x} \mathrm{La}_{x} \mathrm{Fe}_{12-y} \mathrm{Co}_{y} \mathrm{O}_{19}$ with $x=y=0(\mathrm{SrM})$ and $x=0.367, y=0.212$ (LaCo5) at $5 \mathrm{~K}$. 


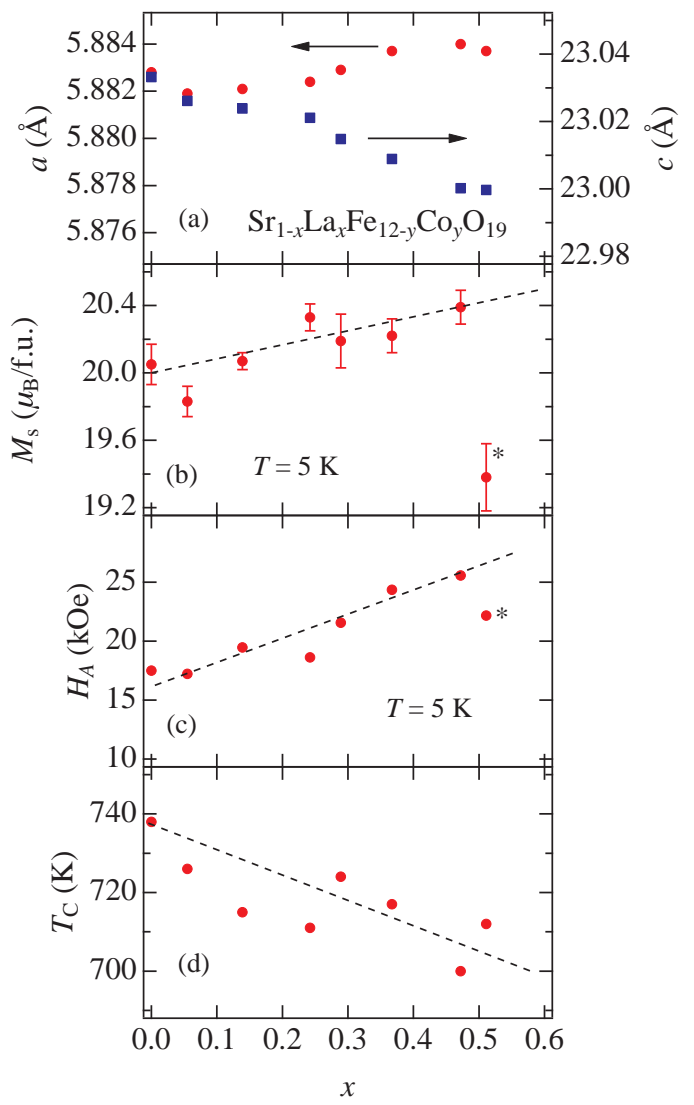

Figure 6: (Color online) La concentration $(x)$ dependence of lattice constants, $a$ (solid circles) and $c$ (solid squares) (a), the saturation magnetization, $M_{\mathrm{S}}(\mathrm{b})$, the anisotropy field, $H_{A}$ (c), and the Curie temperature, $T_{\mathrm{C}}(\mathrm{d})$ for $\mathrm{Sr}_{1-x} \mathrm{La}_{x} \mathrm{Fe}_{12-y} \mathrm{Co}_{y} \mathrm{O}_{19}$. Dashed lines are the guide for the eye. 